Int. J. Electrochem. Sci., 15 (2020) 5031 - 5041

International Journal of

ELECTROCHEMICAL

SCIENCE

WWW.electrochemsci.org

\title{
Superior Cycle Stability of Single Crystal Nickel-Rich Layered Oxides with Micron-Scale Grain Size as Cathode Material for Lithium Ion Batteries
}

\author{
Cheng Yang ${ }^{1,2, *}$ Zhenhua Zhu ${ }^{3}$, Weifeng Wei ${ }^{2}$, Liangjun Zhou ${ }^{2, *}$ \\ ${ }^{1}$ School of Metallurgy and Environment, Central South University, Changsha 410083, P.R. China \\ ${ }^{2}$ State Key Laboratory of Powder Metallurgy, Central South University, Changsha, Hunan, \\ 410083, P. R. China \\ ${ }^{3}$ School of Chemistry, South China Normal University, Guangzhou,510006, PR China. \\ *E-mail: alexander-zhou@csu.edu.cn, yangchengcsu@163.com
}

doi: $10.20964 / 2020.06 .03$

Received: 2 February 2020 / Accepted: 17 March 2020 / Published: 10 May 2020

\begin{abstract}
Ni-rich layered transition metal (TM) oxides are being aggressively developed, due to their high volumetric energy density. However, the severe capacity fading hinders their practical applications such as electric vehicles. As reported, grain boundary of primary particles is expected to play an important role in the performance degradation. Here, single crystal $\mathrm{LiNi}_{0.8} \mathrm{Mn}_{0.1} \mathrm{Co}_{0.1} \mathrm{O}_{2}(\mathrm{NCM}, \mathrm{S} 811)$ with a grain size of 1-4 $\mu \mathrm{m}$ was synthesized by controlling the Li/TM ratio and two-step calcination. Compared with the common agglomerated NCM811 (A811), S811 exhibited the similar initial specific capacity of 198.9 $\mathrm{mAh} / \mathrm{g}$ at $0.1 \mathrm{C}$, but much higher capacity retention ( $96.2 \%$ after 150 cycles). Further investigations, including morphology analysis, electrochemical tests and observation of internal variation, were carried out to further understand the superiority of S811. The superior performance could be attributed to the better structure stability of single crystal with larger size, which could introduce more $\mathrm{Ni}^{2+}$ in the outer layer for inhibiting the phase transformation $(\mathrm{H} 2 \rightarrow \mathrm{H} 3)$ and side reactions on the interfaces. This work may provide a promising strategy for long-term cycling stability of nickel-rich NCM-type lithium ion battery.
\end{abstract}

Keyword: nickle-rich layered oxides, micron-scale, single crystal, phase transformation, lithium ion batteries.

\section{FULL TEXT}

(C) 2020 The Authors. Published by ESG (www.electrochemsci.org). This article is an open access article distributed under the terms and conditions of the Creative Commons Attribution license (http://creativecommons.org/licenses/by/4.0/). 